was wanted was an experiment to decide between the hypotheses of direct action at a distance and of action
by means of a medium. At the time that Clerk-Maxwell delivered his address,
no experiment was known that could deride between the two hypotheses. Specific inductive capacity, the the time propagation of electro-magnetic actions by
means of conducting material-these were known ; but means of conducting material-these were known; but
he knew that they could be explained by means of ac tion at a distance, and had been so explained. Waves through a medium such as the ether. When we are dealing with a conductor and a thing called electricity running over its surface, we are, of course, postulating a medium on or in the conductor, but not outside it
which is the special point at issue. Clerk-Maxwell be lieved that just as the same air that transmits sound is
able by differences of pressure-i. $e$, by means of its it so the r unit volume-to move trified bodies to move by means of its energy per unit volume. He believed this, but there was no experiment known then to decide between this hypothesis
and that of direct action at a distance, As I have enand that of direct action at a distance. As I have enbetween the hypotheses is possible except an experi-
ment proving propagation in time either directly, or indirectly by an experiment exhibiting phenomena like those of the interference of ligbt. A theorist may ing of a mediun. This is all very well in mathematical formulie; but, as in the case of light, we must con-
sider what becomes of it af ter it has left the sun and before it reaches the earth. So every hypothesis assumwe talk about it or not. There are some difficulties surrounding the complete interpretation of some of but I confidently expect that they will lead to a decision on most of the outstanding questions on the tro-magnetic waves quite analogous to those of light, and that he has proved that electro-magnetic actions are propagated in air with the velocity of light. By ing currents of such frequency that their wave length is only about two meters. I may pause for a minute
to call your attention to what that means. These waves are propagated three hundred thousand kilometers in a second. If they vibrated three hundred kilometer long. This rate of vibration is much highe than the highest audible note, and yet the waves are
much too long to be manageable. We want a vibramuch too long to be manageable. We want a vibra-
tion about a thousand times as fast again, with waves about a meter long. Hertz produced such vibrations,
vibrating more than a hundred million times a second. That is, there are as nany vibrations in one sec-
ond as there are seconds-in a day? No. far more. In a week? No: more even than that. The pendufor four months before it would vibrate as of ten as one
of Hertz's vibrators vibrates in one second. And how did he detect the vibrations and their interference ? that; they should them; they are much too slow for are much to quick for that. If they went a million times more slowly, they would be well heard. He made use of the principle of resonance. You all understand
how by a succession of well timed small impulses a large vibration may be set up. It explains many that a former Marquis of Waterford used the prineiple to overturn lamp posts; his ambition soared above knocker wrenching. So that it is a principle known
to others besides scientific men. Hertz constructed a was the same as that of his generating vibrator, and leaping across a small air space in this resonant circuit. The well timed electrical impulses broke down the air resistance, just as those of my Lord of Waterford broke
down the lamp post. The combination of a vibrating generating circuit with a resonant receiving circuit is one that I spoke of at the meeting of the British
Association at Southport, as one by which this very any feasible way of detecting the induced resonance; I
did not anticipate that it could produce sparks. By its means, however, Hertz has been able to observe the reflected waves. He placed his generating vibrator
several wave lengths away from a wall, and placed the receiving resonant circuit between the gene-
ratorand the wall, and in thisair space he wasable to rator and the wall, and in this air space he was able to from his generator they reappeared, to disappear again in regular succession at equal intervals between his
generator and the wall. It is exactly the same phenogenerator and the wall. It is exactly the same pheno-
menon as what are known as Lloyd s bands in optics. a reflected wave. It follows hence that, just as Young's prove the undulatory theory of optics, so Hertz's experi-
ment proves the ethereal theory of electro-magnetism. It is a splendid result.

Henceforth I hope no learner will fail to be im-
pressed with the theory-hypothesis no longer-that all known space, and that it is the same medium as the one by which light is propagated; that non-conductors has taught us, transmit electro-magnetic energy. By means of variable currents energy is propagated into
space with the velocity of light. The rotation of the of its magnetic poles. This seems a hopeful direction in which to look for an explanation of the secular precession of terrestrial magnetism. It is quite different perfect conductor. If this were true there would be a pair of great antipoles outside the air, and terrestrial think the earth would have stopped rotating long ago. by submerging one or more metallic plates or masse

IT is well known that considerable difficulties a lightships, and even with lighthouses on rocks at a dishowever, devised a method of effecting the object robably be applicable to other purposes. He point ut that at the present time, wherever electric telehore and a lighthouse, either floating or on a rock at distance from the shore, it is effected through an inculty is experienced, owing to the rapid wearing of th comes on, and when, liable to break whenever a stor e in proper working order. By his invention he is tion and distant point without metallic connection on the other. This is effected in the case of a light from each plate or sets of plates he leads an insulate conductor to a telephone in the lighthouse. A two conductor cable is led from a signal station on the one of the conductors of the cable is led to a metallic plate submerged on one side of rock at such a distance from it as to be in water deep enough for it not to be affected by waves. The other conductor of the cable is similarly led to another metallic plate or mass simiTo communicate from the shore to the lighthouse, an
of the rock. interrupter or reverser and battery are connected to the shore ends of the two insulated conductors, and the

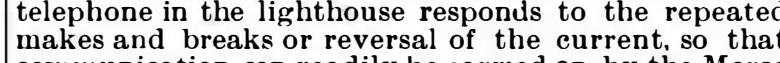
communication can readily be carried on by the Morse alphabet. If a vibrating interrupter or reverser be intervals. A more convenient way is to use two finger keys, one of which by a series of teeth on its stem, or in other more convenient way, produces a few breaks
or reversals of the current, while the other key when depressed produces a greater number of breaks or re versals. In the same way communication could be
carried on from the shore to a vessel at a distance from
it if the vessel were in the vicinity of two submod plates or anchors, each having an insulated conductor passing from it to the shore, and if two metallic plates were let go from the vessel, so that these plates might be at a distance apart from one another. The position of the two submerged plates coupled to the submerged this way communication might be effected between and a moored lighthouse or signal station. A similar result might be obtained with a single insulated conductor from the shore by the use of an induc tion apparatus with the ends of the secondary winding coupled by insulated conductors to
at a distance apart.-Electrician.

CHEAP APPARATUS FOR GENERATING SULPHURETED HYDROGEN.

By J. Martin, Lecturer at the Diocesan College,

THE apparatus shown below for generating $\mathrm{H}_{2} \mathrm{~S}$ for and has given the greatest satisfaction on the score of

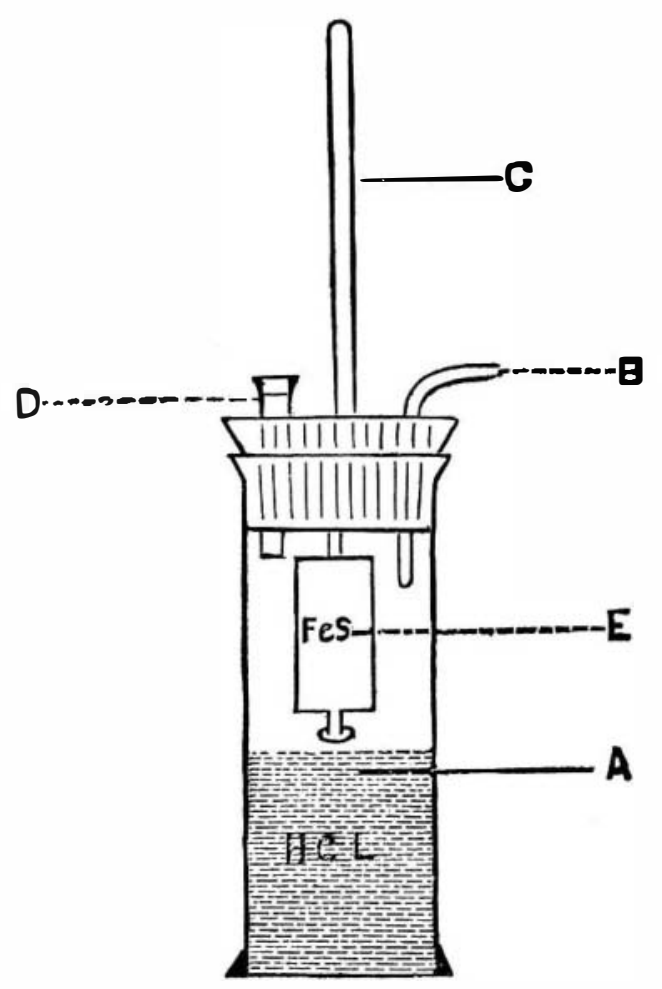

both cheapness and convenience. The diagram will ufticiently explain its action.

A is a large glass cylinder, such as is used for deflag-
ration experiments, tightly fitted with a well paraffined cork with three holes. C is a stout glass rod which passes through the center hole in the cork and through a hole in the bottom of a cylindrical porcelain vessel,
$\mathrm{E}$, which is supported by the end of the rod being flat tened. The bottom of the porcelain vessel is drilled
with several small holes. $B$ is the delivery tube for with several small holes. $B$ is the delivery tube for the gas, and $\mathrm{D}$ is a short wide tube so placed that its
lower end is perpendicularly over the interior vessel
and closed at the to 0 with a cork. The gas is, of course, generated by placing Fes in the porcelain vessel, and acid in the lower part of the plass cylinder, and pushing down the rod. The strength of the current can be regulated with considerable nicety. To
charge the apparatus for use I take out the cork from the tube, $\mathrm{O}$, and drop in suall pieces of FeS, which fall into the porcelain vessel. The acid is sent in through ing. When the acid is the first to be used up, I draw up tube, $D$, and invert the whole apparatus. The liquid,
of course, runs out, but the FeS is retained so as to fall of course, runs out, but the $\mathrm{FeS}$ is retained so as to fall I find that friction is sufficient to support the FeS, but to prevent accidents I place a small piece of caouthouc tubing on the rod above. The whole apparatus only costs about three shillings.
It can, of course, be made of all sizes.-Chem. News.

\section{EXAMINATION OF HONEY.}

By K. KaTsER.

THE residue from the fermentation of pure honey is,
a rule, optically inactive, and, if heated with hydroas a rule, optically inactive, and, if heated with hydroeductive sugar. Sieben's first two methods for the ollows : 25 grms. honey are mixed with 12 grms. solid
yeast (free from starch), and made up with water to 200 
c. c., and let ferment for forty-eight hours at a medium temperature. Aluminum hydroxide is then added
and the mixture made up to 250 c. c.; 200 c. c. of the clear filtrate are concentrated to $50 \mathrm{c}$. c. and polarized in a 200 mm. tube A deflection of more than $1^{\circ}$
(Wild) proves that starch sugar has been added. 25
c. c. of the liquid used for polarizing are then mixed c. c. of the liquid used for polarizing are then mixed
with 25 c. c. water and 5 c. c. strong hydrochloric acid and heated for an hour in a boiling water bath, neutral ized, made up to 100 c. c., and any sugar formed is determined by Allihn's method in one-quarter of the
liquid. The sugar thus found, multiplied by 40 , gives the quantity of sugar which comes to the fermentation residue from 100 grms. of honey. If thi
per cent., starch sugar has been added.

A NEW METHOD OF DETERMINING LITHIUM BY MEANS OF FLUORIDES.

THE spectroscope gives valuable indications for the qualitative detection of lithia, but a comparison of
the intensity of the spectral rays gives merely a doubtespecially if more than a few milligrammes per liter are
present. The reagent used is ammonimu fluoride. As the commercial salt is often contaminated with fluo-
silicate, it is purified as follows: Some grammes of the silicate, it is purified as follows: Some grammes of the salt are dissolved in a sumall volume of water, a double
volume of ammonia is added, the whole is boiled for a vow seconds, let cool, filtered, and washed with ammofuoride in a strong ammoniagl solution, which served in a covered platinum crucible. If we have in solution a few decigrammes at most of a salt of lithium with quantities of other alkaline salts not more than solution is reduced to a few c. c. in a tared platinum ia are added up to a volume of 15 to $20 \mathrm{c}$ c. The whole is well mixed and let settle, when there is formed a white gelatinous precipitate, scarcely visible, of of the capsule. The next day it is complete, when we decant alrnost all the liquid upon a very small filte and pour in its place a few c. c. of ammoniacal water
and ammonium fluoride, stir up with a platinum spatula and let settle. Soon afterward we make a secwith a few drops of the same reagent. Thus we re move all the soluble alkaline salts, and we have, partly
on the filter and partly in the capsule, all the lithium on the filter and partly in the capsule, all the lithium salt imbued merely with ammonia and ammonium drops of dilute sulphuric acid, and all the liquid is nited gently until all acid vapors have completely disappeared and the residue is weighed as neutral lithium sulphate. To take account of the solubility of lithium
fluoride in the ammoniacal liquid, its total volume is measured, ranging from 30 to 50 c. c. According to
former results, and remembering that the washing waters remained in contact with the precipitate for a contains approximately 2 milligrammes lithium fluoride $=4$ milligrammes sulphate or 1 milligramme lithia
The quantity thus calculated is added to that weighed The quantity thus cal
directly.-A. Carnot.

ON RHINANTHIN.

By Dr. T. L. Phipson, F.C.

In my Journal of Medicine, etc. (No. 100, p. 66), I talin in the leaves of the Antirrhinum majus. which flourishes abundantly in the sandy soils of Surrey. Further investigation of this substance has shown me years ago by an Austrian chemist, H. Ludwig. from the
seeds of Rhinanthus hirsutus and R. crista-galli (Rattle). Rhinanthus hirsutus and $R$. crista-gall leaves and stalks of the Antirrhinum mains (snapbe recognized, even when present in very minute quan tity in an aqueous solution. According to my experi-
ments, rhinanthin can be extracted from the plant ments, rhinanthin can be extracted from the plant
either by means of methylic alcohol or by cold water. either by means of methylic alcohol or by cold water.
The former process gives the larger yield, but the latter gives a purer product, and is in every respect easie and more economical. The plant, when fresh, is very fragments, leaves and stalks, and allowed to remain in
water in a closed vessel for a few days. The liquid is then filtered, treated with a small quantity of sub-acetate of lead (which does not precipitate rhinanthin), filtered again, and the slight excess of lead having rated carefully (on a water bath) almost to sirupy consistency, and then the vessel is allowed to remain in a warm, dry place for a few days. In these circumstances
rhinanthin forms transparent colorless rhombic crysrhinanthin forms transparent colorless rhombic crys-
tals, which are very brilliant; it can be purified by a second crystallization from water. It has a peculia

in alcohol.
The aqueous solution of rhinanthin, to which a few
drops of hydrochloric acid are added and then heated, drops of hydrochloric acid arre added, and then heated, gradually turns brown, finally deposits an amorphous natant solution contains glucose. in appearance to the brown tint developed in solutions of glucose heated with soda (for instance, diabetic by acid. A perfectly clear, colorless solution of rhinan$\mathrm{HCl}$ and heated, turns gradually brown, and in a few
$\mathrm{H}$ moments, just after the solution has reached its boiling tate of rhinanthogen results, in the form of a dark red.
dish brown amorphous powder, which can be filtered off and washed. The filtrate contains glucose.

phuric acid, forming a greenish black solution. It is also attacked easily by nitric acid.
Ludwig has given to rhinanthin the formula
$\mathrm{C}_{58} \mathrm{H}_{62} \mathrm{O}_{40} ;$ my analyses of this substance do not $\mathrm{C}_{64} \mathrm{H}_{68} \mathrm{O}_{40}$.

Nevertheless, I have not had sufficient of the product In treating the decoction by subacetate of lead, it is In treating the decoction by subacetate of lead, it is
well to employ as little as possible; the slight excess of
lead can be removed either by carbonate of soda, phosphate of soda, or sulphureted hydrogen. I prefer th latter, though it leaves a small quantity of acetic acid
free in the liquid to be evaporated ; for I have found by direct experiment that dilute acetic acid will not even after boiling for a considerable time; and on the
water bath the presence of a minute quantity of free acetic acid is not, in this case, prejudicial. It is best not to evaporate to a thick sirup, but to stop as soo as indications of crystallization occur at the edge of
the liquid. The capsule is then removed to a warm, tals thus formed are very white and brilliant

The genera Rhinanthus, Antirrhinum, and Digitalis
all belong to the same family of plants, and probably perhaps the toxic properties of Linaria (another closely perhaps the toxic properties of Linaria (another closely
allied genus) are due to it. But whatever may be its allied genus) are due to it. But whatever may be its ige digitalin, is very liable to allotropic changes and ubstanees extracted from Digitalis are really derived rom allotropic or isomeric changes and from the de composition of digitalin, and that these changes oceir during the elaborate processes of extraction.-Chem A New Catalogre of Valnable Papers

Contained in Scientific American Supplement during the past ten years, sent free of charge to any
address. MUNN $\mathrm{CO}$., 361 Broadway, New York.

\section{THE SCIENTIFIC AMERICAN}

\section{Architects an Builders Edition}

\section{$\$ 2.50$ a Year. Single Copies, 25 cts.}

This is a Special Edition of the ScIENTIFIC AMERIEach number contains about forty large quarto pages equal to about two hundred ordinary book pages, forming, practically, a large and splendid Magazine in colors and with fine engravings, illustrating the most interesting examples of
Construction and allied subjects.

A special feature is the presentation in each number of a variety of the latest and best plans for private residences, city and country, including those of very ings in perspective and in color are giver, together
with full Plans, Specifications, Costs, Bills of Estimate, and Sheets of Details.
No other building puper contains so many plans, details, and specifications regularly presented as the SCIENTIFIC AMERICAN. Hundreds of dwellings have already been erected on the various plans we have
issued during the past year, and many others are in
process of construction. Architects, Builders, and Owners will find this work all who contemplate building or improving homes, All who contemplate building or improving homes, or
erecting structures of any kind, have before them in examples from which to make selections, thus saving
this work an and end series of the lant Many othery.

Many other subjects, including Sewerage, Piping,
Lighting, Warming, Ventilating, Decorating, Laying Lighting, Warming, Ventilating, Decorating, Laying Compendium of Manufacturers'Announcements is also given, in which the most reliable and approved Build-

makers, etc.
The fullness, richness, cheapness, and convenience of
this work have won for it the Largest Circulation this work have won for it the Largest Circul
of any Architectural publication in the world.

MUNN \& Co., Publishers,

361 Broadway, New York

A Catalogue of valuable books on Architecture Building, Carpentry, Masonry, Heating, Warming, ertaining to the art of Building, is supplied f $f_{1} e$ of harge, sent to any address.

Building Plans and Specifications. In connection with the publication of the BuILDINe EDITION of the SCIENTIFIC AMERICAN, Messrs. Mun of every kind, including Churches, Schools, Stores, Dwellings, Carriage Houses, Barns, etc.
In this work they are assisted by able and experienced architects. Full plans, details, and specifica-
tions fcr the various buildings illustrated in this paper cans $\mathrm{fcr}$ the various buildings illustrated in this pape
The supplied. Those who conteuplate building, or who wish to whether wings, porches, bay windows, or attic rooms,
whens whe invi wd to communicate with the undersigned.
Our work extends to all parts of the country. Esti mates, plans, and drawings promptly prepared. Term oderate. Address

MUNN \& CO., 361 BROADWAT, NEW YORK.
T II 1

Scientific American Supplement. PUBLISHED WEEKLY.

Terms of Subscription, $\$ 5$ a year.

Sent by mail, postage prepaid, to subscribers in any ear, sent, prepaid, to any foreign country.

All the back numbers of THE SUPPLEMENT, from the commencement, January 1, 1876, can be had. Price All the back volumes of The Supplement can likewise be supplied. Two volumes are issued yearly.
Price of each volume, $\$ 2.50$ stitched in paper, or $\$ 3.50$

Combined RATES.-One copy of Scientific AMERICOMBINED RATES.- One copy of SCIENTIFIC AMERI-
CAN and one copy of SCIENTIFIC AMERICAN SUPPLEA one year, postpaid, $\$ 7.00$.

A liberal discount to booksellers, news agents, and

MUNN \& CO., Publishers,

361 Broadway, Now York, N. Y.

TABLE OF CONTHNTS.

RBORICULTURE.-Fruit Growing in the West Indies--The ex-
portof bananas and oranges to this country.-'The quantity of the
crop.- - tilluyration.

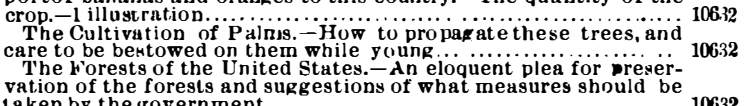

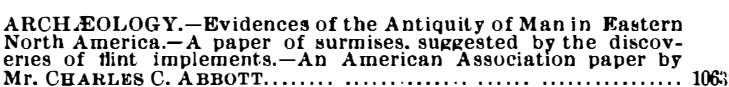

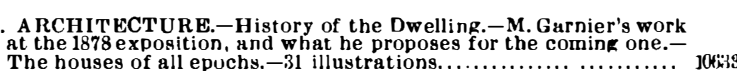
CHEM ISTRY.-A New Method of Determining Iithium by
Means of Hluorides.-Precipitation and separation of lithium as thuoride.

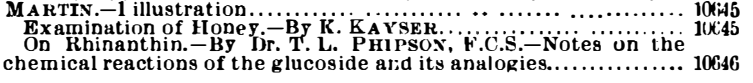

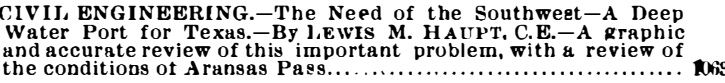

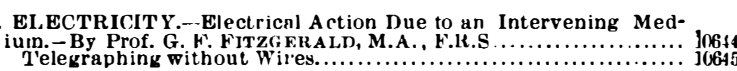

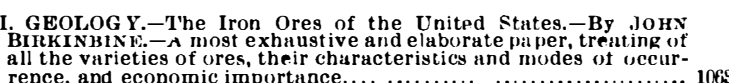

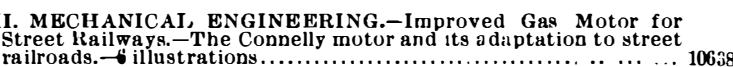
MISCELLANEOUS.-An Ancient Geographer-J -Johann Schoner
of Carlstadt and his work in the 16th century.-His account of $M a-$

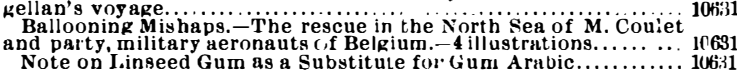

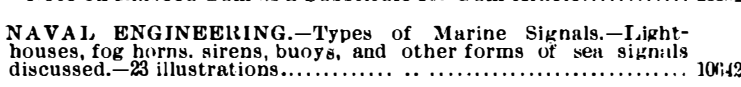

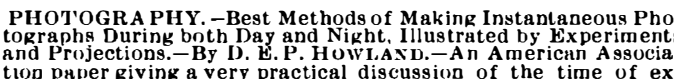

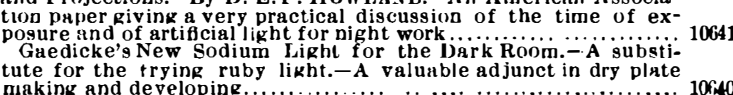

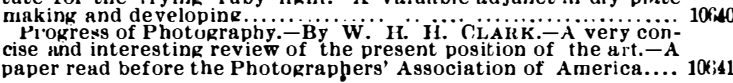

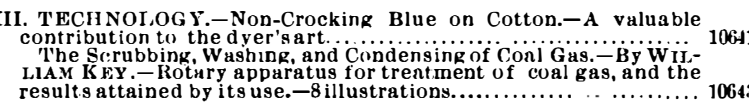
Useful Engineering Books Manufacturers, Agriculturists, Chemists, Engineers men, of all classes, need good books in the line of their respective callings. Our post office department permits mall cost. A comprehensive catalogue of useful books by different authors, on more than fifty different subjects, has recently been published, for free circulation, names of author. Persons desiring a copy have only
to ask for it, and it will be mailed to them. Address,

MUNN \& CO., 361 Broadway, New York.

\section{PATENTS.}

In connection with the Scientific A merican Messrs. MUNN \& Co. are solicitors of American and
Foreign Patents, have had 42 years' experience, and now have the largest establishment in the world. A special notice is made in the Scientific American of all inventions patented through this Agency directed to the merits of the new patent, and sales or Any perion often easily effected.

Any person who has made a new discovery or inven
ion can ascertain, free of charge, whether a patent

We also send free our Hand Book about the Patent Laws, Patents, Caveats, Trade Marks, their costs, and

MUTISI de 00. 361 Broadway, New York.

Branch Office, 622 and 624 F St., Washington, D. C. 